\title{
Role of Min Bao in Creating Public Opinion for the Revolution of 1911
}

\author{
Zhang Yongxia \\ School of Arts and Law, Wuhan University of Technology, Wuhan, China, 430070
}

Keywords: Min Bao; The Revolution of 1911; creation of public opinion

\begin{abstract}
As an official organ of Tongmenghui, Min Bao played an important role in creating public opinion for the revolution of 1911. This paper expounds the historical background at that time and how Min Bao created public opinion, and then clarifies why this magazine has had such a wide influence. Through introducing revolution situations and social ideological trends in foreign countries and infusing revolutionary thoughts into the readers, Min Bao inspired revolutionaries to fight for the revolutionary ambitions with the spirit of sacrifice and striving, thus helping them to shape their life value outlooks, form their revolutionary convictions and develop their revolutionary behavior patterns.
\end{abstract}

\section{Introduction}

The Revolution of 1911 was a milestone in China's history. In reviewing the course of the Revolution of 1911, Sun Yat-sen spoke highly of the role of bourgeois revolutionary newspapers and magazines in promoting the revolutionary cause [1]. The bourgeois revolutionist Feng Ziyou once said, "The foundation of Republic of China should be attributed to the military actions and the propaganda by the Chinese Revolutionary Party, between which the propaganda was more powerful and widely-influenced." Among various bourgeois revolutionary newspapers and magazines, Min Bao played a great role in promoting the dissemination of bourgeois democratic revolutionary thoughts, eliminating the reformers' pernicious influence, of the reformists, facilitating the formation of the revolutionary spirit, and improving the revolutionary situation.

As far as previous researches concerned, it can be learned that Min Bao has attracted extensive attention from the field of history and the field of journalism, which also highlights the research value and historical value of Min Bao [2]. However, the researchers mainly focus on the propaganda of Min Bao for the Three People's Principles. Also, some researchers study the relation between Min Bao and several figures such as Sun Yat-sen and Zhang Taiyan, and some other researchers discuss the debate between Min Bao and Xin Min Cong Bao and its outcome. As most of the previous researches just make a shallow introduction and description about Min Bao, which means they are introductory researches or sporadic researches, in-depth discussion on Min Bao remains lacking, especially the reasons why it can cause a sensation after its sudden emergence. Therefore, the in-depth discussion in this paper is helpful for us to recognize the extensive influence of Min Bao on the revolution of 1911 and its historical status.

\section{Background where Min Bao Created Public Opinion for the Legitimacy of Revolution}

After the Opium War, the crisis of the Chinese nation had been deepening, and the ideological trend of salvaging China from subjugation had emerged in the society. The ideological trend changed a lot after the Sino-Japanese War of 1894-1895, compared with that before the war. Generally speaking, before the Sino-Japanese War of 1894-1895, the Chinese society was led by the ruling class [3]. For example, the enlightened group from the landlord class headed by Lin Zexu and Wei Yuan proposed that the Chinese people should open their eyes to the outside world and learn from foreign countries to beat them, and the westernization group from the landlord class headed by Zeng Guofan, Li Hongzhang and Zhang Zhidong launched the westernization movement, aiming at enriching the country and strengthening the army. However, both the two groups are inseparable from the acquiescence and advocacy of the Qing government. On the other hand, the ideological 
trend changed a lot after the Sino-Japanese War of 1894-1895, in that the vast majority of modern intellectuals began to lead the campaigns of the constitutional monarchy or the Manchu-expelling revolution. In the Sino-Japanese War of 1894-1895, the Qing government, which regarded itself as the Celestial Empire, was defeated by Japan, which was regarded as just an east island, and was forced to sign the Treaty of Shimonoseki that humiliated the country and forfeited its sovereignty [4]. The shock resulted from losing the Sino-Japanese War greatly exceeded that resulted from any similar political event before in scale and degree. The defeat left the Chinese people endless shock, sadness and disappointment. In this situation, the Chinese people, especially modern intellectuals, began to reflect on the traditional political system and tried to use the democratic values of Western countries to build a new political system in China. As Liang Qichao said, "It is the loss of the SinoJapanese War of 1894-1895 that wakes China up from the dream of four thousand years. Against this background, modern intellectuals started to spread their various thoughts widely through newspapers and magazines.

\section{Support of Public Opinion Provided by Min Bao for the Revolution of 1911}

As an official organ of Tongmenghui, Min Bao was the most powerful propaganda tool for the bourgeois revolutionaries. Min Bao grew out of China of the 20th Century started by Song Jiaoren, Huang Xing and Chen Tianhua in Tokyo in June 1905. 24 issues were published from 1905 to 1908. Later, Wang Jingwei published another two issues overseas, so a total of 26 issues were published [5].

The Three People's Principles and revolutionary ideals advocated by Sun Yat-sen were of course not limited to pure theories and the grand propaganda of saving the country and building the country, but included strong attacks by newspapers and magazines like Min Bao on actions that violated or obstructed the lofty ideals. Only in this way could the heated mood and the revolutionary aspirations without hesitation be triggered. The support of public opinion provided by Min Bao for the Revolution of 1911 should include the following three points at least: first was to provide guidelines for revolution; second was to relentlessly expose the actions that hindered the achievement of the lofty revolutionary ideals; the third was to introduce revolution situations and social ideological trends in foreign countries, in order to inspire revolutionaries to fight for the revolutionary ambitions with the spirit of sacrifice and striving, and thus help them to shape their life value outlooks, form their revolutionary convictions and develop their revolutionary behavior patterns [6].

The Six principles of Min Bao, which was written by Hu Hanmin after a discussion among the major members of Tongmenghui, could be regarded as the programmatic document of Min Bao and the declaration of its political position. The six principles summed up by Hu Hanmin are: first, to overthrow the evil government of the time; second, to build a republican government; third, to nationalize the land; fourth, to maintain the true peace of the world; fift, to advocate the connection between the Chinese people and the Japanese people; sixth, to ask for foreign countries to support China's revolutionary cause. That article also explained that the first three principles reflected the internal policies of Tongmenghui and the other three principles the external policies, but it stressed that the six principles can be combined into a major one, namely revolution-Min Bao was published for revolution and was published for people to know the revolution. Hu Hanmin wrote, "If the Chinese people can read Min Bao and can know the principles of Min Bao, then the revolution is likely to succeed." It can be learned that the main purpose of Min Bao was to propagandize the bourgeois revolutionist's ideas to promote the revolutionary movement.

Moreover, Min Bao, an official organ of Tongmenghui, also shouldered the task of propagating the revolutionary programs of Tongmenghui, just as Man Hua said, "We were determined to start Min Bao, the purpose of which was to propagandize revolutionary theories and clarify the Three People's Principles." In the foreword to the first issue of Min Bao, Sun Yat-sen made further elaboration on the 16-character guiding principle of Tongmenghui and he summarized the three major principles, namely nationalism, democracy and the people's livelihood, for the first time, which signaled the birth of the Three People's Principles. The Three People's Principles reflected 
Sun Yat-sen's basic political ideas at the stage of the democratic revolution of the old type, which also served as the guideline of Tongmenghui [7]. Sun Yat-sen pointed out that the basic task of Min Bao was to infuse the theories and ideals of innovation and revolution into the Chinese people's minds make them gradually become the common sense, so that the practical revolution could be predictable. In Sun Yat-sen's opinion, the starting of Min Bao is for the purpose of propagandizing revolutionary ideas and the Three People's Principles to promote the revolutionary practices. Just as he wrote, "When the early writers such as Hu Zhantang, Wang Jixin, Zhu Zhixin and Song Dunchu wrote profound and ingenious articles for Min Bao, they all believed that the purpose of the articles was to clarify the Three People's Principles."

The revolution needed not only the guidance of rational revolutionary programs, but also the stimulation of hot encouragement. Due to the articles full of passion published in Min Bao, the revolutionary trend spread throughout the country. Sun Yat-sen considered Min Bao the most successful magazine since magazines could be published freely, and described the situation as "So many righteous people at that time took actions when they heard about the publication of Min Bao. They did not decline to shoulder the responsibility and put forward their unique proposals for the revolution in Min Bao." Students also welcomed the publication of Min Bao in 1905, and they paid their compliments to Min Bao in different ways [8]. For example, a reader wrote to the editorial office, "Min Bao has received extensive publicity from both the compatriots living at home and those living abroad, which I cannot fully describe using my words. Even experienced scholars are longing for a copy of Min Bao and they will treasure it when truly receiving it." In addition, we can also learn the masses' revolutionary fighting spirit from the anniversary celebration of Min Bao in 1906, as Jing Meijiu, a staff of the magazine, recalled, "Mr. Sun made an elaborate discussion on the Three People's Principles, especially on the people's livelihood in his two-hour speech. As a great speaker, Mr. Sun spoke with a calm attitude and a fresh voice, and the audience's welcome to the speech went without saying." Many attendants donated for Min Bao. As the first donator, Luo Junze donated 10 Japan Yen to show his support for the donation and said, "Min Bao is the most likable and most credible magazine for us...we should actively take measures and consider the articles in Min Bao and the cost of Min Bao to be our own affairs." It can be learned that through propagandizing revolutionary guidelines and revolutionary remarks of Sun Yat-sen and other leaders, the power and influence of Min Bao were enlarged, and it inspired people's fighting will and formed their revolutionary spirit. Later, when Sun Yat-sen recalled the Wuchang Uprising, he said, "I think the success of the Wuchang Uprising is due to the revolutionaries' spirit. According to traditional Chinese military theories, the party that possesses "xianshen" has advantages over the opposite party, and "xianshen" just means the spirit."

During the first decade of the 20th century, in order to safeguard its rule and especially to meet its needs as an imperialist government, the Qing government implemented the so-called New Deal and the Preparation of Constitutionalism. The government established provisional assemblies in many provinces, and planned to hold a congress to set up a responsible cabinet [9]. With these selfrescue programs, the late Qing government put a coat of restoration on itself and also brought about some mirages to the royalists and the constitutionalists at that time. However, the progressives and revolutionaries with calm observation and objective analysis were not deceived by the lip service of the Qing government. In Zhu Zhixin's article published in the first issue of Min Bao titled The Qing Government Is Impossible to Develop into a Constitutional Government Even If It Would Like to, he wrote, "Considering that the Qing government has caused such heavy damage to the country, can we imagine that it can develop into a constitutional government by itself? No, we must strengthen our resolve of revolution." and "There are no precedents in the West that set up constitutions before revolutions." Wang Dong published the article Discussion on the Necessity of Revolution before China Sets up Constitutions in the second issue of Min Bao with the pseudonym Jishen. Although the author was young, his writing style very incisive. He supported the revolution in China by making a profound theoretical exposition of the objectivity, inevitability and urgency of the revolution, and advocated that the pursuit of a constitutional government should be after the national revolution. Besides, Wang Jingwei wrote My Words to Those Who Hope the Qing 
Government to Set up Constitutions, Xuanjie wrote Refutation of the Legal News: Discussion on the Qing Government Setting up Constitutions, and so on. The revolutionaries recognized that the essence of the Qing government setting up constitutions was for the purpose of safeguarding its autocracy, and that the royals were impossible to give up or reduce their political interests and material benefits. Therefore, the Chinese people shouldn't anchor their hope of China's progress on the Qing government, and more importantly, they shouldn't hesitate for the constitutional monarchy, which could be at the cost of the good opportunities of China's development. Just as Chen Tianhua wrote in his article published in the first issue of Min Bao titled Reasons Why a Democratic Regime Is Suitable for China, "One cannot expect a more likable or more suitable regime than republic." and "If the Chinese people are determined to establish a republic government, we must develop what need to be developed and abolish what need to abolished resolutely without basing on the old government." In order to establish a republic government, the Chinese people must overthrow the Qing government and establish a new one instead of just improving the political structure of the old government. This meant the Chinese people should expel Manchu from China and establish a Han China, meant the Chinese people should overthrow the autocracy of the Manchu aristocracy, and meant the revolution was inevitable.

By revealing the political fraud of the false constitutionalism, Min Bao helped the Chinese people to recognize the essential purpose of the constitutionalism of the Qing government. It was in order to safeguard its rule that was in danger, to appease the reformists and win their support, and to delude the revolutionaries that the Qing government threw out the cover of constitutionalism. This political fraud once brought some illusions to the reformists and consequently obstructed their thinking and actions for saving the country and the people. This false constitutionalism was nothing but self-deception for China at that time. Therefore, the revolutionaries published lots of articles in Min Bao shortly after it was started to reveal the political fraud of the false constitutionalism of the Qing government, helping the Chinese people to gradually recognize the purpose and motive of the constitutionalism of the Qing government and setting the direction and goal of the revolution. The deception of the Qing government put itself to the opposite of the Chinese people, intensified the public appointment to the government, and thus firmed the people's beliefs in revolution.

When the Hundred Days' Reform had failed, in order to achieve their goal, the royalists who lacked political support turned their eyes to the propaganda with newspapers and magazines and considered initiating the national wisdom to be the most important point. Since 1899, Kang Youwei and Liang Qichao had been raising funds to start overseas royalist newspapers and magazines. They started New China's News, Datong Daily and Xin Min Cong Bao in Japan and the United States, among which Xin Min Cong Bao, which Liang Qichao started in Japan in 1902, was the most notable one. Xin Min Cong Bao was allowed to be publicly sold in China, and it had a number of agencies at home and abroad. Due to these two conditions, and Liang Qichao's higher and higher reputation for writing, the circulation of Xin Min Cong Bao was around 10,000 and the magazine had a considerable influence on intellectuals. Since the reformism advocated by Xin Min Cong Bao hindered the development of the democratic revolutionary movement, an intense debate between Min Bao and Xin Min Cong Bao broke out. In the extra to the third issue of Min Bao, the debating outline was listed out. Min Bao argued with Xin Min Cong Bao on the different topics from its fourth issue. From 1905 to 1907, the two magazines conducted a major debate on a series of major issues at that time. The debate mainly focused on the following three points: whether the revolution was necessary; whether the civil rights should be strengthened; whether the feudal land ownership should be changed.

The constitutionalists and the revolutionaries belonged to two different political groups, so the political debate was inevitable. Although the two groups both aimed at salvaging China from subjugation, opposing the autocratic monarchy, and reforming China, the main divergence between the two groups lay in that the revolutionaries saw expeling the Manchu by means of armed struggle as the starting point, and in contrast, the constitutionalists advocated peaceful petitions for constitutionalism. The sales volume of Xin Min Cong Bao was quite large at its early stage, the peak of which was as high as 15,000 , as Feng Ziyou commented, "Over the first two years since 
Xin Min Cong Bao was started, Liang Qichao spared no effort to expound and propagate nationalism. The destruction view he proposed was particularly intense, and exerted a quite great influence on the domestic young people's thoughts." However, Liang Qichao later was affected by Kang Youwei's counterrevolutionary remarks, and the articles he published in Xin Min Cong Bao changed both in contents and views. Particularly, Liang Qichao's Argumentation for Enlightened Autocracy and Kang Youwei's Discussion on the History of the French Revolution strongly aroused people's disgust. Moreover, during the later part of the debate, Liang Qichao encountered the embarrassing situation that his inspiration had dried up, and the sales volume of the magazine also declined to only 3,000 to 4,000. Eventually, the publication of Xin Min Cong Bao had to be stopped, and the debate come to and end with the revolutionaries' comprehensive victory. Man Hua commented, "When Min Bao was started, it first cleared away reactionary remarks with incisive analysis, and then made clear the true meanings of revolutionary theories. The situation that most of the Chinese Students studing in Mishima are attracted by the revolution with unbridled enthusiasm should be attributed to Min Bao." In summary, through the debate between the reformists, Min Bao cleared away counterrevolutionary remarks, strengthened the direction of the revolution, and mobilized the forces of the revolution.

Fourth, Min Bao introduced revolutionary situations, socialist ideological trends and anarchic ideological trends in foreign countries, and thus provided a platform for the Chinese people to learn about overseas situations.

Min Bao introduced revolutionary movements in foreign countries, mainly focusing on the French Revolution, the Russian Revolution of 1905 and the Indian Independence Movement, especially the French Revolution. Both articles and pictures were used to introduce the Great French Revolution in Min Bao. The articles included Ma Junwu's Biography of the Founder of the Republic of France Gambetta, Wang Dong's Discussion on the History of the French Revolution, and Bo Yang's Discussion on Declaration of the Rights of Man and of the Citizen, etc. The pictures included the portrait of Rousseau, who was the top scholar about democratism, the real scenes of the French Revolution, the front view of the Triumphal Arch, the picture depicting the storming of the Bastille on July 14th 1789, the picture depicting a juvenile army going out to battel during the French Revolution, etc. Through introducing the revolutionary movements in foreign countries, especially the French Revolution, Min Bao helped the Chinese people to learn about the outside world, broadened their horizons, and activated their thoughts.

Besides, Min Bao also translated and introduced various socialist theories including Marxism, state socialism and anarchism. The socialist ideological trend propagandized by the revolutionaries was closely linked with the Principles of People's Livelihood which was just the Japanese translation of socialism. The revolutionaries attempted to incorporate some socialist ideas into the future scheme of establishing Republican of China, thus they combined the pursuit of the bourgeois democracy with the propaganda of socialism. Min Bao published a number of articles that introduced socialism, such as Zhu Zhixin's Collected Biographies of Several German Socialists and Advances of Britain's Labor Party in the Recent Presidential Election, Liao Zhongkai's Outline of the History of Socialism and Anarchism and Socialism, and Song Jiaoren's Russian Revolution of 1905, A Brief History of the Congresses of Socialist Parties in Different Countries, and Discussion on Socialism. These articles were the source of the socialist ideas that later spread across China. Undoubtedly, these socialist ideas were relatively defective compared with those the Communist Party of China believed in later, but these articles truly reflected the deep sympathy of the revolutionaries of that time to the low-class people, and showed their lofty ideals of pursuing a just and equal society. The revolutionaries provided more possibilities for the Chinese people with these articles when they were going on the journey of saving the country and the people from peril.

Since started in 1905, Min Bao Had publish 21 images and 24 articles about nihilists, anarchists and Chinese revolutionary martyrs such as Wu Yue, Qiu Jin and Xu Xilin from the 2nd issue to the 26th, namely final issue. Min Bao sometimes introduced anarchism as a school of socialism, and their introduction and propagation of anarchism were totally out of their admiring the foreign anarchists' spirit of bravery and fighting instead of their believing in anarchism. Min Bao published 
lots of excellent articles and excellent images about nihilists' assassinations, especially the domestic emergencies such as Wu Yue's bombing at five officers, Qiu Jin's sacrifice for her plotting uprisings in Zhejiang Province, and Xu Xilin's assassinating a provincial governor Enming in Anqing, for the purpose of stimulating the Chinese people to continue fighting with the Qing government. Zhang Taiyan, once influenced by anarchism, wrote many articles on anarchism, such as Without Five Things, Theory of the State and Prelude of Anarchism. Zhang Taiyan wrote the articles on anarchism mainly out of dissatisfaction with capitalism. He thought that some phenomena in capitalist societies were contradicted to freedom, equality and philanthropism, and wanted to use this ideological trend of thought to attack the bourgeoisie and its political representatives. However, Zhang Taiyan thought anarchism was not suitable for China, so he abandoned it after April 1908. The spirit of fearlessness and the siprit of sacrifice from anarchism encouraged the Chinse people to implement assassination and uprisings, thus providing more means and methods for revolutions and the opposition to the Qing government.

\section{Analysis of the Reasons why Min Bao Had Such an Extensive Influence on the Revolution of 1911}

First, Min Bao had a clear revolutionary stand and high combat effectiveness. The 20th century is the century of revolution. Revolution is the trend of the 20th century and the trend of the development of the history. The history had proven that the constitutional monarchy was not feasible in China, so Min Bao just held the pulse of the age and followed the trend to propagandize revolutionary remarks and revolutionary guidelines, and thus it was sure to be chosen by the history and welcomed by the masses. Besides, the articles in Min Bao were usually with clear purports and presented the authors' viewpoints at the beginning instead of in a roundabout way, and thus readers could know what the authors wanted to argue as soon as they began to read. Moreover, the articles published in Min Bao included those in classical Chinese that educated people were familiar with, those in vernacular Chinese that was easy to understand, and some novels with wonderful plots and profound meanings. In a word, Min Bao had an overwhelming advantage over newspapers and magazines issued by constitutionalists or other counterrevolutionaries both in contents and writing.

Second, Min Bao assembled a group of excellent writers such as Chen Tianhua, Song Jiaoren, Liao Zhongkai, Wang Jingwei, Hu Hanmin, Zhang Taiyan, Zhu Zhixin, Liu Shipei. These people were all good at writing or even well-known for writing. Moreover, they were elites at that time. They once studied in Japan and thus could saw not only the weakness of China and the corruption of the Qing government, but also the trend of the development of the world. Therefore, except for the concerns about China and the Chinese people, they also had radical thoughts of revolution. In addition, most of them were very young. Particularly, the average age of Wang Jingwei, Wang Dong, Hu Hanmin, Chen Tianhua and Huang Xi was just about 22 years old. Therefore, these people who were full of youthful spirit dared to attack the Qing government's corruption, and were willing to sacrifice themselves for the revolution. As a result, the articles publish in Min Bao were quite radical and revolutionary. Min Bao was really fortunate to have assembled these thoughtful people together.

Third, Min Bao had a relatively complete sales network, which was formed in virtue of revolutionaries, revolutionary organizations, friends at home and abroad, and other friendly newspapers or magazines which had the same purport at home or abroad. Therefore, Min Bao soon became popular after its first issue with a larger and larger sales volume. Specifically, the first issue had a first run of more than 5,000 copies, and the second issue and the third issue had both a first run of 10,000 copies and this number was maintained for the following issues, among which the first run of the 18th issue reached the peak of 12,000 copies. Since Min Bao received a wide popularity in the society, the issues would usually be reprinted for many times. For example, the first issue was reprinted for 8 times, the second issue 9 times, and the third issue 8 times. Min Bao also had diverse sales methods and dissemination methods, such as overseas agencies, Kiosks for low-class people and secret dissemination method at home. Rao Futing, a martyr of the Huanghuagang Uprising, recalled, "At that time, the Qing government was very fearful of and 
resentful about Mr. Sun and other revolutionaries, so the magazines propagandizing revolutionary theories were strictly controlled, inspected and blocked. We could just receive the copies from those who had returned from abroad. Even an incomplete copy would we cherish very much and circulate it among us for everyone to read." Rao Futing was just one of the most enthusiastic borrowers. He tried his best to collect all the issues and carefully read them, and thus his will and resolve of revolution was stimulated. Sun Yat-sen also paid much attention to the issue and sales of Min Bao. In September 1905, shortly before Min Bao was started, he wrote to his friends in Singapore and asked them to set up an agency to sell Min Bao, "My comrades and I are going to start a magazine named Xin Bao, which will soon be issued. I wish that you can act as the general agent in Singapore." When Sun Yat-sen propagandized revolutionary ideas to masses, He would also take the opportunity to promote Min Bao. For example, When he refuted the argument of the reformists that the revolution would result in China's being carved up by the powerful foreign countries in a talk with local overseas Chinese people in Seremban, Malaysia in 1906, he did not let the chance go and promoted Min Bao, "Jingwei wrote an article titled Refutation of the Argument that the Revolution Will Result in China's Being Carved up. Buy a copy of Min Bao and you can learn the reasons."

Therefore, through the extensive sales network, many people had access to Min Bao. The masses could learn about the ideas propagandized in Min Bao in time, and thus their revolutionary thoughts could be stimulated.

\section{Conclusion}

To sum up, newspapers and magazines are social weapons, and public opinion is the mother of facts. Through revolutionary newspapers and magazines like Min Bao, Sun Yat-sen and other revolutionaries revealed the political fraud of the false constitutionalism of the Qing government, propagandized the guidelines of the revolutionaries, and created an revolutionary upsurge with the debate between the reformists. Moreover, Min Bao introduced revolutionary situations in foreign countries and some theories of socialism and anarchism, thus encouraging the masses' enthusiasm and boosting the revolution. A reader said with emotion, "The prosperity of Min Bao means the prosperity of the Chinese nation. The prosperity of Min Bao means the prosperity of the Chinese people's freedom and happiness. The prosperity of Min Bao means the elimination of slavery and the prosperity of personalism. The prosperity of Min Bao means the elimination of hegemonism and the prosperity of humanism....Not being wood or stones, human beings have conscience, so there cannot be any traitor who does not feel excited when he has read Min Bao...The day Min Bao stops issuing is the day the wave of revolution sweeps the world." Under the influence of revolutionary newspapers and magazines like Min Bao, the word "revolution" had been deeply inscribed on the Chinese people's hearts, and thus the revolution of 1911 just occurred naturally.

\section{References}

[1] Chan L S. Beyond the Nationalist Narrative: Contextualising the History of the Overseas Chinese Press in Japan[J]. Asian Studies Review, 2017, 41(4): 594-610.

[2] Maras S, Nip J Y M. The Travelling Objectivity Norm: Examining the case of the first Chinese journalism handbook[J]. Journalism Studies, 2015, 16(3): 326-342.

[3] Luan N M, Beng L Y. MALAYSIAN CHINESE LANGUAGE NEWSPAPERS AND NATIONAL IDENTITY: A STUDY OF THE ROLES OF SIN CHEW DAILY IN CHINESE CULTURAL PRESERVATION AND NATION BUILDING[J]. Kajian Malaysia, 2018, 36(1): 63166.

[4] Ma N. The Rise of" Anti-China" Sentiments in Hong Kong and the 2012 Legislative Council Elections[J]. China Review, 2015, 15(1): 39-66.

[5] Zhang Q. New Issues in the Modern History of China[M]//An Introduction to Chinese History 
and Culture. Springer, Berlin, Heidelberg, 2015: 409-439.

[6] Min M. The Mercantile Enlightenment in Late Qing and Early Republican China[J]. Social Sciences in China, 2014, 35(4): 180-200.

[7] Hua L, Galway M. Freedom and its limitations: The contemporary mainland Chinese debate over liberalism[J]. China Information, 2018: 0920203X18760849.

[8] Fu Q. The Gap Between Historical Narrative and Historical Facts: A Re-analysis of Li Xiehe's Political Decisions and Motivations During the Xinhai Revolution (1911)[J]. Fudan Journal of the Humanities and Social Sciences, 2016, 9(4): 663-685.

[9] Chong J I. Popular narratives versus Chinese history: Implications for understanding an emergent China[J]. European Journal of International Relations, 2014, 20(4): 939-964. 